\title{
$J(\Theta)$
}

Received: 28.11 .2019

Accepted: 16.12 .2019

Published: 29.01 .2020

JOTS, 4/1, 2020: 28-38

\section{Türkçede Eyleyensiz Fiiller}

\section{Impersonal Verbs in Turkish}

\author{
Okan ERMAN \\ İ t a n bul/ T u rkey \\ E-mail: okannerman@gmail.com
}

The term of impersonal verb to be used to describe the verbs that do not need any subject to be realized. Until this time, there is no an examine in details about condition of impersonal verbs in Turkish. The reason for this is based on the idea that impersonal verbs are not available in Turkish. However, the results of this article has been revealing that previously mentioned the idea should be criticized. The topic was handled around three important questions: What is impersonal verb? What is the reason for being of impersonal verbs? Are impersonal verbs available in Turkish? We think, the answers given to these questions will contribute to both theoretical linguistics and grammar studies of Turkish.

Key Words: impersonal verbs, Turkish, active voice. 


\section{J(৫)}

\section{Giriş}

Hint-Avrupa dillerinin büyük bir kısminda meteorolojik hadiseleri ifade etme vasıtası olan ve içerik itibarıyla diğer fiillerden ayrışıp eyleyensiz fiiller olarak adlandırılan, oldukça sınırlı sayıda fiil mevcuttur. Eyleyensiz fiilleri (İng. impersonal verbs, Rus. bezliçnıe glagoli) ıralayan, adından da anlaşılacağı üzere, göndermede bulunduğu hareketin gerçekleşmesi için bir eyleyene (fâil) ihtiyaç duymamasidır (Kalyuta 2004: 21).

Söz gelimi İngilizce için;

It rained "Yağmur yağdı"; It snowed "Kar yağdı".

Aynı şekilde Almanca için;

Es regnet "Yağmur yağıyor"; Es donnert "Gök gürlüyor"; Es schneit "Kar yağıyor".

veya Türkçe gibi fiilleri şahıslara göre çekimleyen bir dil olan Latince için;

Pluit "Yağmur yağı̀or".

Yukarıdaki cümlelerin fiilleri eyleyensizdir. İlk cümleyi ele alacak olursak özne konumundaki it göndergesiz olup içi boştur ve cümlede mevcut tek unsur geçmiş bir zamanda gerçekleşen rain fiilidir ve cümleyi Türkçeye çevirdiğimizde karşımıza bir özne olarak çıkan yağmur, yağ- fiiline içkindir. Bir başka deyişle yukarıdaki cümlelerin hepsinin bir öznesi vardır, ancak bu özneler eyleyen yani meydana gelen olayın fâilleri olmayıp zorunluluk gereği mevcutturlar. Çünkü cümlenin cümle olabilmesi için öznenin varlığı şarttır. Alman filozof FIcHTE, dilde edilgen yapının ortaya çıkışının altında eyleyensiz fiillerin göndergesi olan doğa olaylarının yattığını düşünür (Aytaç 2011: 95). Eğer bu görüş doğru ise bu fiillerin oldukça sınırlı olmalarına rağmen dil dizgesi içerisinde hayli önemli bir konumu vardır. Belirtmeliyiz ki fiil söz içinde ancak bir eyleyene bağlı olarak kullanılabildiğinden bu tür fiiller dil mantığına aykırıdır.

Bergamalı Kadri, şöyle der:

“Fiillerüy aķl ķatında on sekiz veche ihtimāli vardur. Zirā fāil ki fiili işleyen kimsedür şundan hāli degül; yā gāyib kimse ola, yā ķatunda hāżır olan kimse ola yā sözi söyleyen kimse ola. 


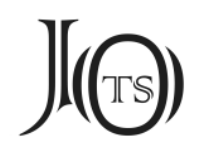

Bu üçden her biricügezi şundan hāli degül ki yā er ola yā avrat ola. Bu ikiden her biricügezi şundan hāli degül, yā bir ola, yā iki ola, yā üç ola ve dahı artuk ola..." (Karabacak 2002: 26)

ve devamında da bu tekil, çoğul ve cinsiyet kategorilerine bağlı olarak fiillerin on sekiz şahıs çekimini sıralar. Peki neden fiiller ancak ve ancak bir kişiye bağlı olarak gerçekleşebilir? Bu sorunun cevabını verebilmek, eyleyensiz fiillerin neliğini kavramak bakımından gereklidir.

Klasik hareket teorisine kısaca değinmek bizler için aydınlatıcı olacaktır. ARisTo'ya göre her hareket eden nesnenin bir şey tarafından hareket ettirilmesi zorunludur (Babür 2005: 305). Yine aynı şekilde PLATON, bir hareket ettirici olmadan hareket eden bir nesnenin var olmasının imkânsız olduğunu söyler (Akderin 2015: 72). Yani hareket bir ilinek olup gerçekleşmek bakımından bir şeye muhtaçtır. ARisto ve PLATON'un yukarıdaki ifadelerinde yer alan zorunluluk ve imkânsızlı, bu teorinin deney ve gözleme dayanmayı önsel (a priori) bir usavurma sonucu geliştiğini gösterir. Klasik hareket teorisi, GALiLEo'nun süredurum yasasını ortaya koyuşuna, yani cismin doğal halinin durağanlık değil de hareket olduğunu tanıtlayışına kadar binlerce yıl geçerliğini korumuştur (Adıvar 2000: 133). İște bir cümlenin cümle sayılmasında öznenin yüklemle birlikte olmazsa olmaz unsur addedilmesi bu klasik hareket teorisi ile sıkı sıkıya bağlantılıdır. En basit ifadeyle "hareket" karşılayan sözcük birimi olan fiil söz içinde kullanıldığında varlığını bir eyleyenin varlığına borçludur. Böyle olduğu için de bir hareket ettiriciye, diğer bir deyişle bir eyleyene ihtiyaç duymayan eyleyensiz fiiller dil mantığına aykıııdır. Burada açıklığa kavuşturulması gereken diğer konu ise eyleyensiz fiillerin varlık nedenidir.

İnsan bilincinin yapısı ve işleyişi, doğadan (dış dünya) farklıdır. Dolayısıyla insan bilincinin biçimlendirdiği bir sistem olan dil de doğadan ayrılır (Ülken 1953: 29). İnsan, bir varlığı bir oluşu kavramaya çalışırken o varlığın veya oluşun muhakkak bir nedeni olduğu sayıltısını taşıdığından filozoflarca nedensellik ilkesi ortaya atılmıştır. Bu ilkeye göre her varlık veya olayın mutlaka bir nedeni vardır. Aristo, nedensellik ilkesi uyarınca dört neden öğretisini geliştirmiştir. Şöyle ki her bir varlık, oluş veya durumun dört nedeni vardır ve bu nedenler de maddi neden, biçimsel neden, ereksel neden ve etkin/fâil nedendir (Arslan 2016: 174). Söz gelimi bir sandalyenin maddi nedeni tahta; biçimsel nedeni dört ayaklı ve 


\section{J(৫)}

arkalıklı formu; ereksel nedeni üzerine oturulabilmesi; fâil nedeni ise sandalyecidir. Cümlenin olmazsa olmaz unsuru olan özne işte bu dört neden içerisinde etkin nedene denk düşer. Ancak yukarıda da belirtildiği gibi doğa bilinçten yapı ve işleyiş olarak farklıdır ve bu sebeple de nedensellik ilkesi doğa olaylarında işlememektedir. Doğa olayları vuku bulmak için bir eyleyene değil şartların olgunlaşmasına ihtiyaç duyar. Söz konusu eyleyensiz eylemlerin varlık nedeni işte bu doğa ve bilinç arasındaki zıtlık, dolayısıyla da doğa ve dil arasındaki zıtlıktır. İnsan bu gibi doğa olaylarını bir mantık üzere işleyen dille ifade etmeye kalktığında söz konusu aykırı durum ortaya çıkmaktadır.

Buraya kadar söylenenler şöyle özetlenebilir:

1. Klasik hareket teorisi uyarınca hareket ilinektir ve nedensellik ilkesi gereği bir hareket ettiriciye yani bir nedene muhtaçtır. Fiilin söz içinde bir eyleyen olmadan var olamaması bundandır.

2. Eyleyensiz fiiller gerçekleşmek için bir eyleyene yani bir hareket ettiriciye ihtiyaç duymadıklarından, nedensellik ilkesi üzere işleyen bilincin biçimlendirdiği dilin mantığına aykırıdır.

3. Eyleyensiz fiillerin göndergesi olan doğa olaylarında nedensellik ilkesi işlemez. Yani doğa olayları gerçekleşmek için bir etkin nedene ihtiyaç duymaz. Eyleyensiz fiillerin varlık nedeni işte bu dil ve doğa arasındaki zıtlıktır.

Yukarıda eyleyensiz fiillerin neliğinin ve var olma nedeninin açıklanmış olduğunu düşünüyoruz. Böylece eyleyensiz fiillerin Türkçedeki durumlarını incelemeye geçebiliriz.

\section{Türkçede Eyleyensiz Fiiller}

Gül Işık Türkçede eyleyensiz fiillerin bulunmadığını savlar: “Örneğin öteki batı dillerinde olduğu gibi İtalyancada da meteorolojik olayları belirten eylemler eyleyensizdir, Türkçede ise eyleyensiz bir eyleme rastlanmaz:

piove - yağmur yağıyor

tuona - gök gürlüyor" (Işık 2012: 75) 


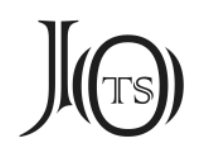

Ve ardından da Türkçenin fiili eyleyensiz bırakmayı kabul etmediğini belirtir. Gül Işık'ın bu yargısı, gerçekten de herhangi bir Batı dilinden eyleyensiz fiilli bir cümle ile bu cümlenin Türkçe çevirisini karşılaştıran bir kimse için ilk bakışta aksi düşünülemeyecek bir gerçek gibi durmaktadır. Fakat Türkçede eyleyensiz eylemlerin bulunmadığı yargısı bizce doğru değildir. Çünkü dil ve doğa arasındaki zıtlık evrenseldir ve dolayısıyla her dil sahibi için geçerlidir. Böyle olduğundan eyleyensiz bir fiili eyleyensiz kabul etmemek herhangi bir dil için söz konusu olamaz. Bu yanılgının sebebi, örneğin Türkçe yağmur yağıyor cümlesinde özne konumundaki yağmur'un yanlış olarak yağmak işinin eyleyeni addedilmesidir ve bunun neden yanlış olduğu aşağıda gösterilecektir. Ancak ondan önce şunu belirtmek gerekir ki eyleyensiz fiillerin Batı dillerinde olduğu hâliyle Türkçede bulunmadığ doğrudur. Bu farklılığı şöyle açıklayabiliriz: Batı dillerindeki eyleyensiz fiiller nesnelerine sımsıkı bağlı olup başka bir nesneye ilişmeyi kabul etmemektedir. Böyle olduğundan nesneleri ile birleşerek bağımsız bir kavram yani bir sözcük birimi teşkil ederler. Örneğin, İngilizce rain sözcük birimi yağmak ve yağmur kavramlarını birleştirerek bir bütün olarak içerir ve bağımsız bir kavram olan yağmur yağmak'ı karşılar. Buna karşın Türkçede eyleyensiz eylemler birden çok nesneye ilişebilmektedir. Söz gelimi yağ- eylemi yağmur dışında kar ve doluya da ilişmektedir. Böyle olduğundan bağımsız bir yağmur yağmak kavramı, dolayısıyla da böyle bir sözcük birimi Türkçede mevcut değildir. Ne var ki bu farkll1klar eyleyensiz fiillerin Türkçedeki mevcudiyetini şüpheye düşürecek nitelikte değildir. Öyleyse Türkçede eyleyensiz fiillerin bulunmadığı, Türkçenin fiili eyleyensiz bırakmayı kabul etmediği yanılgısının kaynağı nedir? Bu sorunun cevabı, bir başka yanılgı olan Türkçede çatı eki almamış fiil kök veya gövdesinin etken çatı kabul edilmesidir. DENiz YILMAZ, bu yanlış görüşü şöyle serimler:

\footnotetext{
"Kedisine çatı biçim birimi getirilmemiş fiil gövdesi, geleneksel Türk dili araştırmacıları tarafından 'esas çatı şekli' ya da 'etken çatı şekli' kabul edilir. Bükünlü Hint-Avrupa dilleri araştırmacılarından dil olgularına tasvirci yaklaşımla eğilen dilci Türkologlarca aksiyom olarak Türkçeye aktarılan etken çatının anlamı, eylemle bağıntıda bulunan nesnenin, eylemin edeni olduğunu bildiren soyut imgedir.
}

Türkçede etken çatının varlığını kabul etmek, çatı eki ulanmamış fiil gövdesinin söylevde sıfır ek (görevsel sıfır ek, anlamlı yokluk) ile temsil edilip işlediğini hem de bu sıfır ekin, yukarıda da belirttiğimiz üzere, eylemle bağıntıda olan nesnenin eden olduğunu bildirdiğini kabul etmek demektir. Güneş battı, okudum, okuyan öğrenci, çalsşacak adam gibi örnekler, 


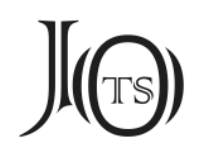

bu görüşü destekler niteliktedir. Verilen örneklerde eylemle bağıntıda bulunan, sırasıyla güneş, -m, öğrenci ve adam göstergeleriyle karşılanan nesneler, gerçekten söz konusu eylemlerin edenidirler, diğer bir deyişle bu nesneler söz konusu anlatımlarda eden rolündedirler. Ancak, söylemek ihtiyacı, okuyacak kitap, söylemedik laf, oturduğumuz ev gibi öbekler, bu görüşe aykırı düşer ve fiil gövdesinin çatı sıfır göstergesine sahip olmadığına ve dolayısıyla eylemle nesne arasındaki bağlantının karakterini bildirmediğine, diğer bir deyişle söz konusu anlamı iletmeye ilgisiz olduğuna işaret eder. Bu son örneklerde, görüldüğü üzere, eylemle bağıntıda bulunan nesne olan ihtiyaç, kitap ve laf, anlatımlarda eden değil edilen; ev ise eylemin geçtiği yer rolünde faaliyet göstermektedir. Söylenenden hareketle Türkiye Türkçesinde etken çatı yoktur." (Deniz Yılmaz 2012: 107)

Türkiye Türkçesinde etken çatının mevcut olmadı̆̆ı yargısı, görüldüğü üzere ciddi bir temellendirmeye dayanmaktadır. Yukarıdaki açıklamadan şu sonucu çıkarabiliriz: Eğer söz konusu çatı eki almamış bir fiil kök veya gövdesi ise Türkçede özne ve eyleyen (fâil) bir ve aynı şey değildir. Bu yargı, Türkçede eyleyensiz fiillerin Batı dillerindekinin aksine kendine özgü var oluş biçimini açıkça ortaya koyduğu gibi eyleyensiz fiillerin var oluş biçimi de bu yargıyı kuvvetle destekler. Sonuç olarak diyebiliriz ki Türkçede eyleyensiz fiillerin bulunmadığı yanılgısı, çatı eksiz fiil kök veya gövdesinin etken çatı işlevi gördüğü, dolayısıyla da böyle bir eylemle ilişkide bulunan nesnenin, sözdizimsel açıdan özne konumunda olmasının o eylemin eyleyeni olduğunu gösterdiği kabulüne dayanır ki bu kabul gerçekle örtüşmemektedir.

Türkçede eyleyensiz fiillere geçmeden önce bir açıklama yapmakta fayda var. Ortaya konmaya çalışıldığı üzere eyleyensiz fiille ilişkide bulunan nesnenin özne konumunda olması aynı zamanda o fiilin eyleyeni olduğu anlamına gelmemektedir. Öyleyse bu nesne anlatımda neden özne konumundadır? Eyleyensiz eylemlerin ilişkide bulunduğu nesne Batı dillerindeki gibi fiile içkin olmadığından anlatımda ya özne ya tümleç konumunda olmak durumundadır. Ne var ki bu eylemlerin ortak özelliği geçişsiz olmalarıdır ve dolayısıyla da ilişkide bulunduğu nesnenin tümleç olması mümkün değildir. Bu sebeple de edenlik bağıntısı iletmeksizin özne konumundadır.

Türkçede, bizce dört eyleyensiz fiil mevcuttur: yă̆-, bit-, doğ- ve karla-. Çalışmanın bu kısmında söz konusu fiiller incelenecek olup ileri sürülen sava dair veriler sunması sebebiyle Dîvânu Lugâti't-Türk'ten (DLT) faydalanılacaktır. 


\section{J(৫)}

\section{1. (yağmur, kar, dolu) yağ-}

\section{Yağmur yağdl}

Bu cümlenin öznesinin yağmur olduğu, ancak yağmurun, yağmak işinin eyleyeni olmadığı açıktır. Çünkü mantık uyarınca bir işin eyleyeni o işi işlemeden önce mevcut olmak zorundadır. Eş deyişle eyleyen, fiilin bildirdiği hareketin zamansal öncelidir. Fakat bir nesne olarak yağmur, yağmak işinden önce değil onunla eş zamanlı var olur ve bu durumda yağmak işinin eyleyeni olması mümkün değildir. yağ- fiilinin ettirgen çatısı için DLT’te verilen cümleler ilgi çekicidir:

Tepri yagmur yagıttı "Tanrı yağmur yağdırdı" (Ercilasun-Akkoyunlu 2015: 332); Tenyri yagmur yagturdı “Tanrı yağmur yağdırdı” (Ercilasun-Akkoyunlu 2015: 387)

Klasik hareket teorisinde Tanr, ilk hareket ettirici (devindirici) olarak yer alır. Şöyle ki her hareket edenin bir hareket ettiricisi, her hareket ettiricinin de bir hareket ettiricisi vardır ve bu silsile olarak devam edip ilk hareket ettirici olan Tanri'da son bulur. Kaşgarlı Mahmud'un, bu konuda herhangi bir açıklamada bulunmamışsa da, verdiği bu örnekte yağmak işinin teşvik ettiricisi, yani ikinci dereceden eyleyeni olarak Tanrı'yı alması, ilk yani asıl eyleyen mevcut olmadığından o silsilenin çözümlenemediğini gösterir.

\section{2. (tohum, ot) bit-}

\section{Ot bitti}

Cümlenin öznesi ot kelimesidir. Ancak ot, bitmek işinin eyleyeni değildir. Çünkü yağ- fiilinde de açıklandığı gibi eyleyen eylemin zamansal önceli olmak zorundadır ve burada açıktır ki ot, bitmek işiyle eş zamanlı veya ondan sonra var olmaktadır. Bu madde başı için yazarın verdiği bilgi oldukça değerlidir: "Herhangi bir şey biter (bitki), doğar veya yaratılırsa Kıpçak lehçesinde bütti denir" (Ercilasun-Akkoyunlu 2015: 324). Bu açıklama, Türkçe konuşanlar tarafından eyleyensiz fiillerin denk düştüğü olgunun ne derece kavrandığını ve Batı dillerindeki gibi sadece meteorolojik hadiselerle sınırlanmayıp bir bütün olarak dil ve doğa arasındaki zıtlık ilişkisine vakıf olunduğunu açıkça ortaya koymaktadır. 


\section{J(G)}

\section{3. (insan yavrusu) doğ-}

Doğ- fiili, ilişkide bulunduğu nesnesinin bizzat dil sahibi insan olması dolayısıyla diğer eyleyensiz fiillerden farklılık gösterir. Nitekim bu fiil Batı dillerinde eyleyensiz fiiller sınıfında yer almaz. Öyle görünüyor ki insanın kendi var olma koşulu olan doğmak işi, eyleyensiz fiillerin, o dil mantı̆̆ına aykırılı̆̆ından ve belirsizliğinden kurtarılmak istenmiştir. Örneğin İngilizce ve Almanca konuşurları bu eylem yerine edilgen çatısını kullanarak anneyi bir eyleyen olarak ön plana çıkarırlar:

Baby was born

Baby wurde geboren

Yukarıdaki cümlelerin harfiyen çevirisi bebek doğuruldu olacaktır. Bu anlatımın Türkçe eş değeri ise bebek doğdu'dur.

Ancak doğ- fiili, Türkçe konuşanlar tarafından böyle bir yola sokulmamıştır. Çünkü yukarıda belirtildiği üzere çatı eksiz Türkçe fiil kök ve gövdeleri Batı dillerindekinin aksine etken çatı anlamı ile işaretli olmadığından buna gerek duyulmamıştır.

Bebek doğdu, cümlesinin öznesi olan bebek, doğmak işinin edeni değil edilenidir. Bu bakımdan Batı dillerinin aksine Türkçede eyleyensiz bir fiildir. Ancak doğ- fiilini diğer eyleyensiz fiillerden ayıran bu özel durum Türkçede de etkisini göstermiştir denebilir. Şöyle ki doğ- fiilinin ettirgen çatılı biçimi olan doğur-, biçimsel olarak ettirgen çatılı olsa da bu işlevi kaybetmiş, başka bir deyişle doğurfiilinin doğ- ile özdeşliği bozulmuş, bağımsız bir sözcük birimi hüviyeti kazanmıştır. Nitekim Kaşgarlı Mahmud, bazı ettirgen çatılı fiillerin ettirgenlik bağıntısı iletmediğini belirtir ve şu örnekleri verir:

Tegri meni kutgardı "Tanrı beni kurtardı"; Er katgurdı "Adam katıla katıla güldü”. (ErcilasunAkkoyunlu, 2015: 291)

O kadar ki doğurmak işini doğmak işinden ayrıştırmak üzere Eski Türkçede ayrı bir geçişsiz fiil dahi mevcuttu: yeni-

Uragut yenidi “Kadın doğurdu”. (Ercilasun-Akkoyunlu 2015: 386) 


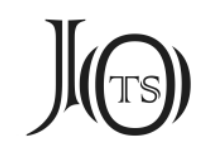

Söz konusu fiilin geçişsiz olduğu ettirgen çatılı biçiminden anlaşılmaktadır:

Er uragıtnı yenitti “Adam kadını doğurttu”. (Ercilasun-Akkoyunlu 2015: 332)

Doğur- fiilinin ettirgen çatısı günümüz için doğurt-, Eski Türkçe için ise togtur-'dur:

Tegri ogul togturdı "Tanrı kadına çocuk doğurttu”. (Ercilasun-Akkoyunlu 2015: 282)

Kaşgarlı'nın togtur- fiili için yaptığı açılamadan togtur-'un, tog- fiilinin değil togur- fiilinin ettirgen çatısı olduğu, dolayısıyla da togur- fiilinin bir fiil gövdesi olarak kabul edildiği anlaşılmaktadır.

\section{4. karla- (kar yă̆-)}

Türkçedeki eyleyensiz fiiller içerisinde özel bir konumu olan bu sözcük birimi, tıpkı Batı dillerindeki eyleyensiz fiiller gibi hareketle (yağmak), o hareketin ilişkide bulunduğu nesneyi (kar) bünyesinde birleștirip bir bütün halinde bağımsız bir kavram olarak iletir. Kar yağ- anlamındaki karlamak sözcük birimi, diğer eyleyensiz eylemler gibi geçişsiz bir eylemdir. Ancak kelimenin DLT'teki kullanımı farklıdır. Örnek cümlede bir eyleyen mevcuttur: bulıt

Bulıt karladı, cümlesinin araştırmacılar tarafından yapılan aktarı ve çevirileri sırasıyla şöyledir:

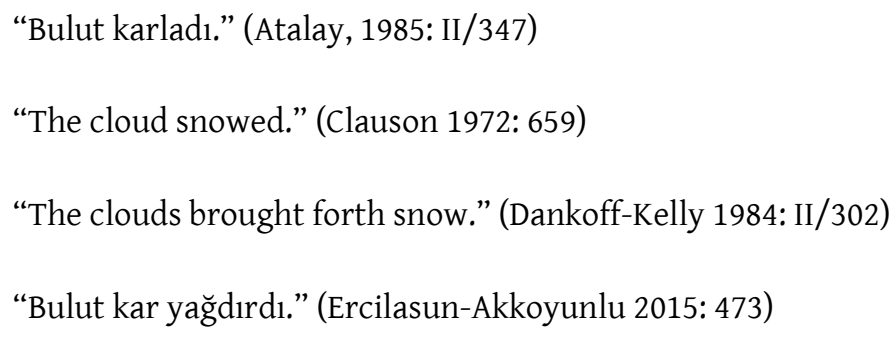

Atalay 1985: II/347 ve Clauson 1972: 659'da cümle kelimesi kelimesine çevrilirken Dankoff-Kelly 1984: II/302 ve Ercilasun-Akkoyunlu 2015: 473'de fiilin ettirgen çatısı tercih edilmiştir. Dolayısıyla cümlede bir eyleyenin bulunmasını, müellifin karla- fiilini geçişli kabul etmesi ile açıklayabiliriz. Ne var ki karla- fiili diğer tüm eyleyensiz fiiller gibi geçişsizdir ki bu, karla- fiilinin ettirgen çatısı için verilen örnekten anlaşılmaktadır: 


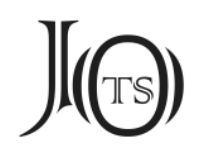

Teyri kar karlattı "Tanrı kar yağdırdı." (Ercilasun-Akkoyunlu: 341)

Bu cümleyi analiz etmek gerekir. Geçişsiz bir fiilin cümle içindeki öznesi, o eylem ettirgen çatıya çevrildiğinde düz tümleç; geçişli bir fiilin cümle içindeki öznesi, o eylem ettirgen çatıya çevrildiğinde ise dolaylı tümleç olur. Yani Kaşgarlı Mahmud karla- fiilini doğru olarak geçişsiz kabul etseydi ettirgen çatısını Tegri bulıt(nı/lǵ) karlattı şeklinde kurması beklenirdi. Ancak fiili geçişli saydığından cümleyi Tegri (bultka) kar karlattı şeklinde kurmuştur. Ne var ki karla- fiili de diğer tüm eyleyensiz fiiller gibi geçişsizdir. Bu açıklama ışığında cümleyi şu şekilde yeniden kurabiliriz:

Kar karladl, cümlesinde, nesne olarak kar, karla- fiiline içkin olduğundan özne konumundaki kar, tıpkı batı dillerindeki benzerleri gibi sözdizimsel bir zorunluluktan var olup tekrardan başka bir şey değildir.

\section{Sonuç}

Eyleyensiz fiiller, iki ayrı işleyiş ve yapıya sahip olan dil ve doğa (dış dünya) arasındaki zıtlığın belirdiği sözcük birimleridir. Bu sözcük birimleri Batı dillerindeki gibi Türkçede de mevcut olup Türkçenin farkı bu kategoriyi meteorolojik olaylarla sınırlandırmamasıdır. Bu noktada tarafımızdan tespit edilen eyleyensiz fiiller yağ-, bit-, doğ- ve karla-'dır. Batı dillerindeki denkleri ile karşılaştırıldığında ilk izlenimin Türkçede bu tür fiillerin mevcut olmadığı yönünde oluşması, çatı eki almamış fiil kök ve gövdelerinin etken çatı bağıntısı ilettiği, dolayısıyla da sözdizimsel bir öge olan özne ile anlambilimsel bir unsur olan eyleyenin, HintAvrupa dillerindeki gibi bir ve aynı şey olduğu kabulüne dayanır.

\section{Kaynakça}

AdIVAR, A. (2000). Tarih Boyunca İlim ve Din, 3. Baskı, İstanbul: Remzi Kitabevi.

AKDERIN, F. (2015). Platon: Timaios, Ankara: Say Yayınları.

ARSLAN, A. (2016). İlkçağ Felsefe Tarihi: Aristoteles III, 5. Baskı, İstanbul: İstanbul Bilgi Üniversitesi Yayınları.

AtalAy, B. (1985). Divanü Lûgat-it-Türk Tercümesi II, Ankara: Türk Dil Kurumu Yayınları. 


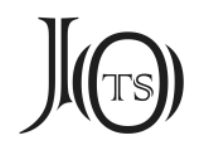

AYTAç, G. (2011). Klasik Alman Dil Felsefesi Metinleri: Herder, Fichte ve Humboldt, Ankara: Phoenix Yayınevi.

BABÜR, S. (2005). Aristoteles: Fizik, 3. Bask1, İstanbul: Yap1 Kredi Yayınları.

ClAuson, Sir G. (1972). An Etymological Dictionary of Pre-Thirteenth Century Turkish, Oxford: Oxford University Press.

Dankoff, R. \& J. Kelly (1984). Mahmut el-Kāşгarī: Compendium of the Turkic Dialects (Dīvān Luyāt at-Türk) II, Harvard: Harvard University Press.

Deniz Yilmaz, Ö. (2012). “Türkçe Kelime Çekimi Ulamları Dizgesi Üzerine: Fiil Çekimi Ulamları", Dil Araştırmaları, 11: 105-129.

ERcilasun, A. B. \& Z. AKKoyunLu (2014). Kâşgarlı Mahmud: Dîvânu Lugâti’t-Türk, Giriş-Metin-Çeviri-Notlar-Dizin, Ankara: Türk Dil Kurumu Yayınları.

ERDEM, M. \& G. COSUN (2013). “Divânü Lügâti’t-Türk'te Ettirgen Yapllar”, Kahraman Maraş Sütçü İmam Üniversitesi Sosyal Bilimler Dergisi, 10/1: 49-58.

Işı, G. (2012). “L. Tesniere’in Yapısal Sözdizimine Göre İtalyanca ve Türkçede Eylem Yapılarının Karşılaştırılması”, Dilbilim, 6: 71-83.

KALYUTA, A. (2004). Dil Bilimi Terimleri Sözlüğü, İstanbul: Multilingual Yayınları.

KaRABACAK, E. (2002). Bergamalı Kadri: Müyessiretü'l-Ulûm: Giriş-Metin-SözlükTerimler Dizini-Tıpkı Basım, Ankara: Türk Dil Kurumu Yayınları.

UlAş, S. E. (2002). Felsefe Sözlüğü, Haz. A. BÂKi GÜçıÜ et al., Ankara: Bilim ve Sanat Yayınları.

ÜLKEN, H. Z. (1953). “Cemiyet ve Dil (Dil Araştırmalarına Rehber Olmak Bakımından)”, Türk Dili Araştırmaları Yıllığı Belleten 1953: 29-44. 